\title{
THE RESPONSE OF GASTRIC INHIBITORY POLYPEPTIDE (GIP) TO ORAL GLUCOSE IN CHRONIC PANCREATITIS: A STUDY BY RADIOIMMUNOASSAY FOR HUMAN GIP
}

\author{
Norihiro Shiga ${ }^{1}$, Tooru Shimosegawa ${ }^{1}$, Hiroaki Akai ${ }^{1}$, Masatoshi Onoda ${ }^{1}$, Hiroyuki Hirano ${ }^{1}$, \\ Takayoshi Meguro ${ }^{1}$, Masaru Koizumi ${ }^{1}$, Takayoshi Toyota ${ }^{1}$ and Noboru Yanaihara ${ }^{2}$ \\ ${ }^{1}$ The Third Department of Internal Medicine, Tohoku University School of Medicine, Sendai, Miyagi 980, and ${ }^{2}$ Laboratory of \\ Bioorganic Chemistry, University of Shizuoka School of Pharmaceutical Science, Shizuoka 422, Japan
}

\begin{abstract}
To investigate the insulinotropic effect of gastric inhibitory polypeptide (GIP) in chronic pancreatitis (CP), we examined the GIP response to $75 \mathrm{~g}$ oral glucose in $18 \mathrm{CP}$ patients and 7 normal subjects (controls) by a radioimmunoassay for human GIP. The GIP response of CP patients was correlated with the pancreatic exocrine function which was evaluated by the caerulein-secretin test (CS test). Plasma GIP concentrations following the oral administration of glucose were higher in CP patients than in controls, but the difference was not significant. When $\mathrm{CP}$ patients were divided into 3 groups according to their exocrine dysfunction (mild, moderate and severe), plasma GIP levels of CP patients with severe exocrine dysfunction were significantly higher than those of controls. No correlation was found between the volume and mean bicarbonate concentration and plasma GIP level at $30 \mathrm{~min}$ after the glucose ingestion. Only the amylase output showed a negative correlation with plasma GIP level. A linear positive correlation was found between the integrated insulin and integrated GIP responses to oral glucose in CP patients with severe exocrine dysfunction, whereas little correlation was observed in those with milder exocrine dysfunction. These data suggest that in $\mathrm{CP}$ patients, endogenous GIP augments the insulin response to oral glucose when pancreatic exocrine insufficiency progresses.
\end{abstract}

A peptide with a potent enterogastrone activity was first extracted from the porcine duodenum by Brown et al. in 1969 (11). Subsequently its amino acid composition and sequence were determined $(6,8,10)$. Because of its inhibitory action on gastric acid and pepsin secretion, this peptide was named gastric inhibitory polypeptide (GIP) $(6,8,42)$, but later studies have clarified another important action on carbohydrate metabolism. GIP is released from the gut by ingestion of glucose or foodstuffs and enhances the insulin secretion as a humoral mediator $(9,14,21)$. GIP has therefore been regarded as a candidate for incretin which is a putative mediator(s) of the entero-insular axis $(16,17)$.

To our knowledge, radioimmunoassays used in the previous studies have all employed antisera against porcine GIP (2). It has been shown that the primary structure of porcine GIP is different from that of human GIP: methionine at position 18 and serine at position 34 of porcine GIP are replaced by asparagine and isoleucine in human GIP, respectively (37). To investigate the role of GIP in the physiology and pathophysiology of man, the development of a radioimmunoassay for human GIP has been desired (2).

Chronic pancreatitis (CP) is a disease of unknown cause in which the pancreatic parenchym is progressively replaced by fibrous tissues, leading to exocrine and endocrine dysfunctions. Different from type 2 (non-insulin-dependent) diabetes mellitus (DM), DM due to CP is caused by impairment of pancreatic endocrine tissues, namely a loss of capacity for producing insulin on demand (19). An insufficiency of insulin and other pancreatic hor- 
mones may therefore alter GIP responses to intestinal luminal stimuli (43). In the present study, using a radioimmunoassay which is specific to human GIP, we studied the GIP response to oral glucose in patients with $\mathrm{CP}$ and in normal subjects.

\section{MATERIALS AND METHODS}

\section{Subjects}

Fifteen male and 3 female patients with CP (13 related to alcohol and 5 idiopathic; mean age $57.0 \pm$ 3.6 years old, range $29-75$ years) who were in stable condition without abdominal pain were investigated. The mean body mass index of these patients was $20.9 \pm 0.5 \mathrm{~kg} / \mathrm{m}^{2}$. The diagnosis of $\mathrm{CP}$ was made based on the radiological findings of pancreatic calcification or irregular dilation of pancreatic ducts observed by endoscopic retrograde pancreatography. The patient's pancreatic exocrine function was evaluated by the caerulein-secretin (CS) test (45). Ten CP patients had overt diabetes mellitus (none had received insulin therapy), 6 were subclinical diabetics and 2 had normal oral glucose tolerance. Thirteen patients had received digestive enzyme replacement therapy and one had received oral hypoglycemic agents, but the medication was halted at least 3 days before the present study. One male and 6 females (mean age $54.0 \pm 2.7$ years old, range 43-63 years old; mean body mass index $21.1 \pm 0.8 \mathrm{~kg} / \mathrm{m}^{2}$ ) without any history of gastrointestinal surgeries, hepatobiliary diseases or metabolic disorders were studied as normal controls.

\section{Caerulein-Secretin Test}

Procedures for CS test After an overnight fast, the patients were intubated with a double-lumen tube which contained duodenal and gastric segments. Under fluoroscopic observation, the tip of this tube was positioned near the Treitz ligament. Thereafter, the patients were allowed to lie in the supine position, and the duodenal juice was collected continuously, while the gastric juice was aspirated separately and discarded. Intravenous injection of caerulein $(30 \mathrm{ng} / \mathrm{kg}$ during $5 \mathrm{~min}$ : Ceosunin, Kyowa-Hakko Kogyo, Tokyo) via a superficial forearm vein was followed by a continuous intravenous infusion of secretin (1.2 CHR unit $/ \mathrm{kg} / \mathrm{min}$ : Secrepan, Eisai Pharmaceutical, Tokyo), and every 10 min fraction of the duodenal juice after caerulein injection was collected for $60 \mathrm{~min}$. These samples were measured for volume, mean bicarbonate concentration and amylase concentration. Bicar- bonate concentration was determined by adding $0.5 \mathrm{ml} \mathrm{samples}$ to $1.0 \mathrm{ml} 0.1 \mathrm{~N} \mathrm{HCl}$ and back-titrating to $\mathrm{pH} 7.0$ using $\mathrm{NaOH}$. Amylase was measured by the blue starch method using a Phadebas Amylase Test (Pharmacia Diagnostic, Uppsala, Sweden).

Grading of exocrine dysfunction The $\mathrm{CP}$ patients were divided into 3 groups according to the degree of pancreatic exocrine dysfunction. Exocrine dysfunction was graded tentatively by the number of impaired factors in the CS test (volume, mean bicarbonate concentration and amylase output of the duodenal juice). The existence of one factor-disorder or no apparent functional impairment was defined as mild dysfunction, a two factordisorder as moderate, and a three factor-disorder as severe exocrine dysfunction. Normal limits for these factors were determined according to the criteria proposed by The Japanese Society of Gastroenterology (47); volume above $1.0 \mathrm{ml} / \mathrm{kg}$, mean bicarbonate concentration above $100 \mathrm{mEq} / \mathrm{l}$ and amylase output above $240 \mathrm{IU} / \mathrm{kg}$ were considered to be within the normal range. Each value in the CS test was calculated as follows: the volume was determined by dividing the total volume of the later 3 fractions (40-60 $\mathrm{min}$ ) of the duodenal juice $(\mathrm{ml})$ by the patient's body weight $(\mathrm{kg})$; the bicarbonate concentration was expressed as the mean value of the later 3 fractions; and amylase output was calculated by dividing the total amylase output (amylase concentration $\times$ volume; $\mu \mathrm{U})$ of the 6 fractions $(0-$ $60 \mathrm{~min}$ ) of the duodenal juice by the patient's body weight $(\mathrm{kg})$. It has been shown that the value of each factor in the CS test decreases as the areas occupied by fibrosis in pancreatic tissues of $\mathrm{CP}$ patients become greater (47).

\section{Plasma Glucose, Insulin and GIP Responses to Oral Glucose}

After an overnight fast, $75 \mathrm{~g}$ glucose (Toleran $\mathrm{G}$, Shimizu Pharmaceutical, Tokyo) was given orally to all subjects. Blood samples were drawn from an antecubital vein before and immediately after the ingestion of glucose, and thereafter every $30 \mathrm{~min}$ for $180 \mathrm{~min}$. Plasma glucose was measured by the glucose oxidase method, and plasma immunoreactive insulin (IRI) by RIA (Insulin Riabead II, Dainabot, Tokyo).

\section{Radioimmunoassay for GIP}

For the determination of plasma GIP concentrations, a radioimmunoassay kit for human GIP 
(Mitsubishi Petrochemical, Tokyo) was employed. A polyclonal rabbit antibody MCR-517, which recognizes the central portion of human GIP(1-42) was raised in New Zealand white rabbits by injecting synthetic human GIP $(1-42)$ which had been conjugated with porcine thyroglobulin by sulfosuccinimidyl 4-( $N$-maleimidomethyl) cyclohexane-1carboxylate (Sulfo-SMCC). This assay system did not cross-react with GIP(3l-42), insulin nor other GIP-related peptides like glucagon, secretin, GLP$1(7-36)$ and GLP-1(7-36) $\mathrm{NH}_{2}$. ${ }^{125}$ I-human GIP( 1 42 ) iodinated by the lactoperoxidase method was used as a tracer, and synthetic human GIP(1-42) as a standard.

The non-extracted plasma samples, $0.1 \mathrm{ml}$ each, were assayed by the double-antibody method, and the obtained values were expressed as $\mathrm{pg} / \mathrm{ml}$. The detection range of this assay system was from 100 to $8,000 \mathrm{pg} / \mathrm{ml}$ of human GIP(1-42). Intraassay and interassay coefficients of variances $(n=5)$ were from 3.5 to $5.5 \%$ and from 5.9 to $8.2 \%$, respectively. When known amounts of synthetic human GIP( 1 42) were added to 3 different samples, the recoveries were 94.6, 98.9 and 92.8\%, respectively.

\section{Calculations and Statistics}

Integrated insulin and integrated GIP responses The integrated insulin and integrated GIP responses were determined, after subtracting the basal values, by calculating the areas under the response curves from 0 to $180 \mathrm{~min}$ after the administration of oral glucose.

Statistics All data in this study are expressed as mean \pm SEM. Data were analysed by one-way analysis of variance (ANOVA) to test the differences between the experimental groups. Individual data of the experimental groups were compared by paired Student's $t$ test. A $P$ value less than 0.05 was considered to be statistically significant.

\section{RESULTS}

\section{Plasma Glucose, Insulin and GIP Concentrations}

Comparison between $C P$ patients as a whole and normal subjects The mean basal glucose levels were not significantly different between $\mathrm{CP}$ patients and normal subjects $(105.1 \pm 5.9$ vs $86.1 \pm$ 3.7 , respectively). After the glucose ingestion, plasma glucose of normal subjects rose promptly and peaked at $30 \mathrm{~min}$, while that of $\mathrm{CP}$ patients rose gradually and reached a maximal level at $120 \mathrm{~min}$.

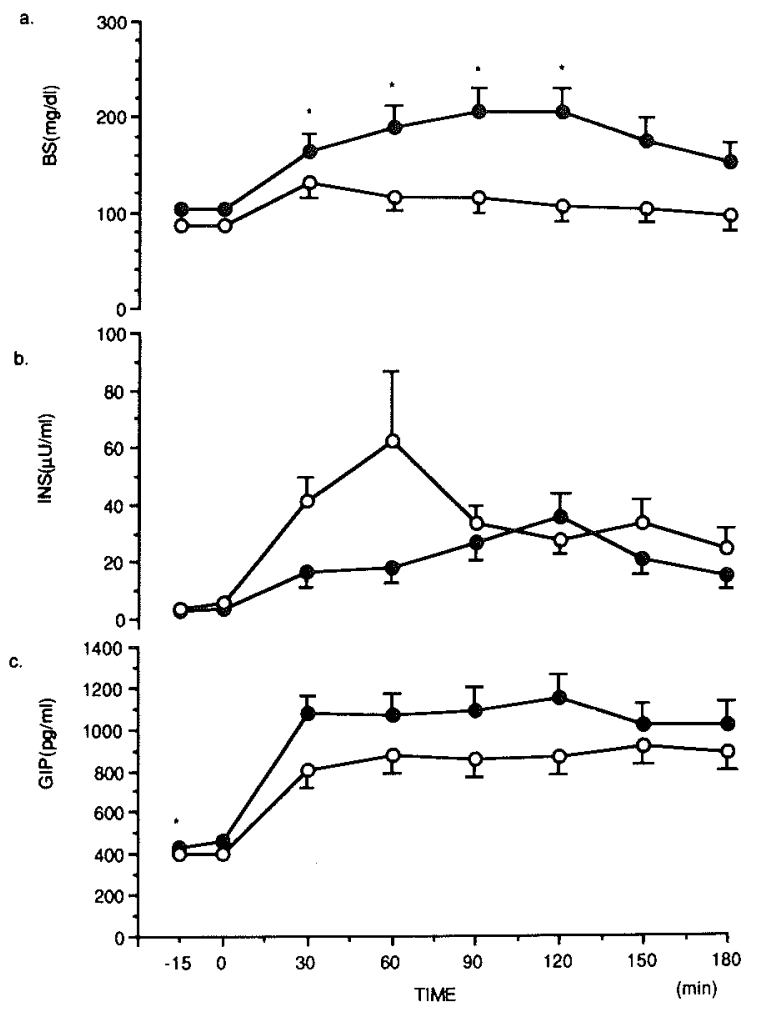

Fig. 1 Comparison of plasma glucose (a), insulin (b) and GIP concentrations (c) in the fasting state and after $75 \mathrm{~g}$ glucose ingestion between chronic pancreatitis (CP) patients (closed circles) and normal subjects (open circles). Glucose was given at $0 \mathrm{~min}$. The stars indicate significant difference between the 2 groups $(P<0.05)$.

At 30,60, 90 and $120 \mathrm{~min}$, the plasma glucose level of CP patients was significantly higher than that of normal subjects (Fig. 1a). Normal subjects showed an early insulin response to oral glucose; plasma IRI reached a peak value at $60 \mathrm{~min}(62.2 \pm 23.1$ $\mu \mathrm{U} / \mathrm{ml})$ and then decreased promptly, but remained at levels higher than the basal until $180 \mathrm{~min}$. In $\mathrm{CP}$ patients, this early insulin response disappeared; plasma IRI rose gradually and peaked at $120 \mathrm{~min}(39.7 \pm 8.5 \mu \mathrm{U} / \mathrm{ml}$ ) (Fig. 1b). Both normal subjects and $\mathrm{CP}$ patients showed prompt rises in plasma immunoreactive GIP (IR-GIP) after the oral glucose administration. At $30 \mathrm{~min}$, plasma IRGIP concentration increased to levels significantly higher than the basal values and thereafter showed plateau. Although the difference was not significant, the plasma IR-GIP concentrations were higher in CP patients than in controls (Fig. 1c).

Comparison between CP patients with or without DM and normal subjects $\mathrm{CP}$ patients were 


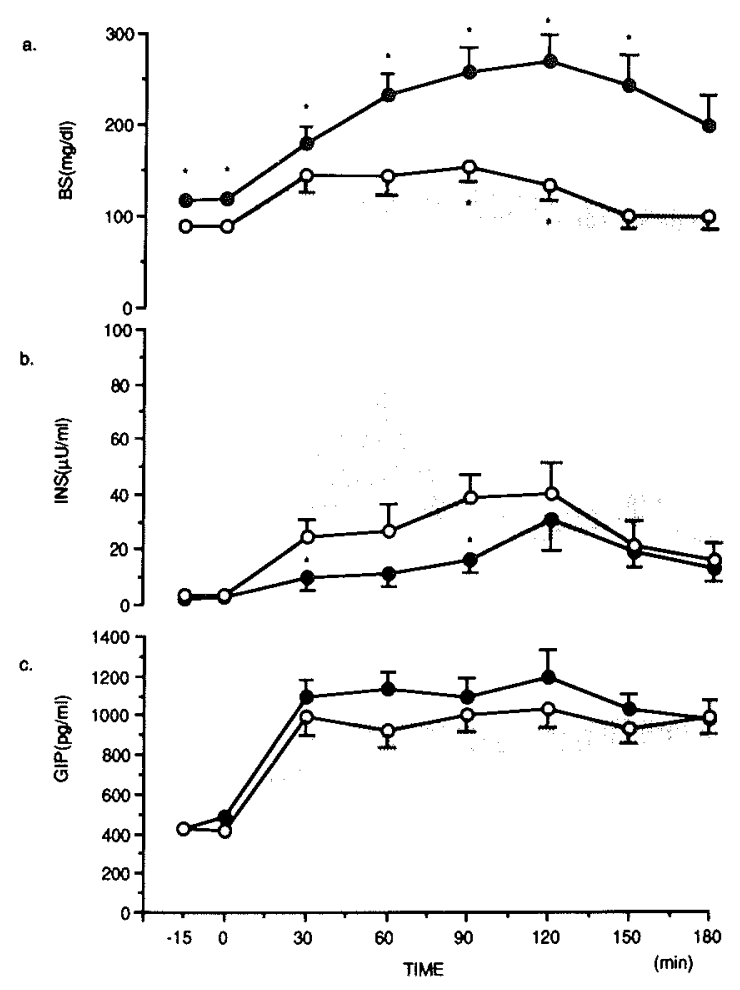

Fig. 2 Comparison of plasma glucose (a), insulin (b) and GIP concentrations (c) in the fasting state and after $75 \mathrm{~g}$ glucose ingestion between $\mathrm{CP}$ patients with diabetes mellitus (DM; closed circles) and those without DM (open circles). Glucose was given at 0 min. The stars indicate significant difference compared with the values of normal subjects $(P<0.05)$. The shaded areas indicate mean \pm 1 SEM of the values in normal subjects.

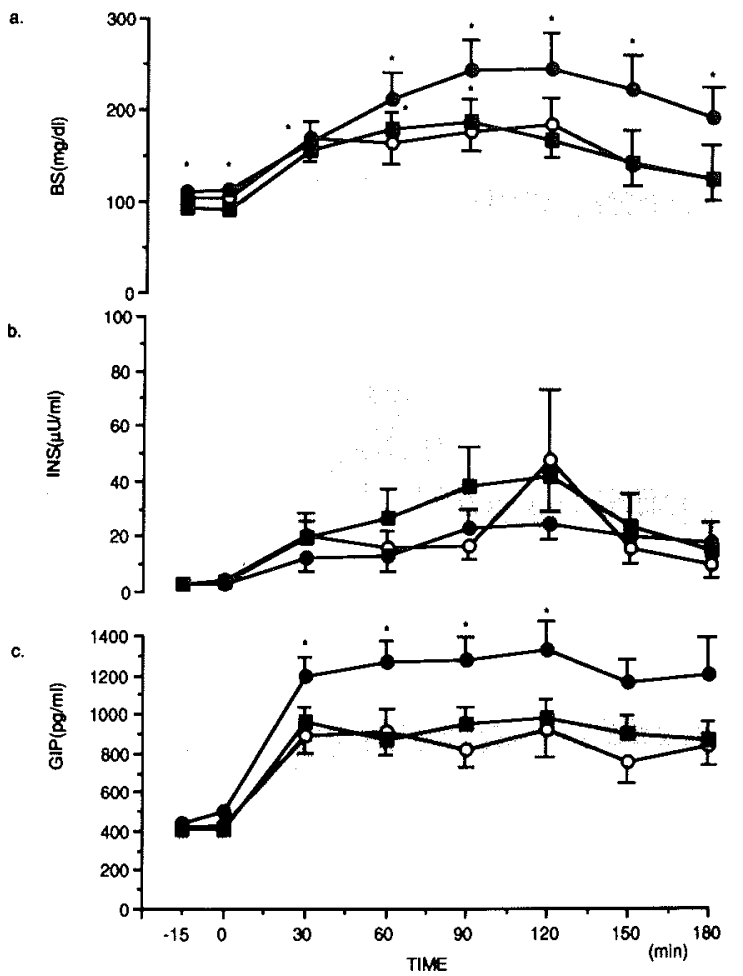

Fig. 3 Comparison of plasma glucose (a), insulin (b) and GIP concentrations (c) in the fasting state and after $75 \mathrm{~g}$ glucose ingestion between CP patients with mild (closed squares), moderate (open circles) and severe (closed circles) pancreatic exocrine dysfunction. Glucose was given at 0 min. The stars indicate significant difference compared with the values of normal subjects $(P<0.05)$. The shaded areas indicate mean \pm 1 SEM of the values in normal subjects.

Table 1 Data of Duodenal Juice in Chronic Pancreatitis Patients with Mild, Moderate and Severe Pancreatic Exocrine Dysfunction and Their Glucose Tolerance

\begin{tabular}{lccccccc}
\hline \multirow{2}{*}{ Exocrine dysfunction } & \multirow{n}{*}{$\mathrm{n}$} & $\mathrm{VOL}$ & $\mathrm{mHCO}_{3}$ & \multirow{2}{*}{ AMY } & \multicolumn{2}{c}{ Glucose tolerance } \\
\cline { 5 - 8 } & & & & & $\mathrm{DM}$ & $\mathrm{IGT}$ & $\mathrm{N}$ \\
\hline Mild & 4 & $1.61 \pm 0.19$ & $94.4 \pm 9.9$ & $337.6 \pm 62.3$ & 2 & 2 & 0 \\
Moderate & 7 & $0.72 \pm 0.13$ & $54.8 \pm 7.2$ & $265.0 \pm 27.5$ & 2 & 3 & 2 \\
Severe & 7 & $0.54 \pm 0.11$ & $30.2 \pm 8.7$ & $122.3 \pm 29.4$ & 6 & 1 & 0 \\
\hline
\end{tabular}

The values of volume (VOL), mean bicarbonate concentration $\left(\mathrm{mHCO}_{3}\right)$, and amylase output (AMY) of the duodenal juice were determined by CS test.

divided into 2 groups according to whether they were complicated by DM or not. The circulating glucose concentrations of $\mathrm{CP}$ patients with DM were significantly higher than those of normal subjects not only in the fasting state but also during 30-150 min after the glucose ingestion (Fig. 2a).
The early insulin response to oral glucose disappeared in patients with and without DM. The insulin response was considerably smaller in $\mathrm{CP}$ patients with DM than in those without DM (Fig. 2b). The fasting IR-GIP concentrations were not significantly different between CP patients with or 


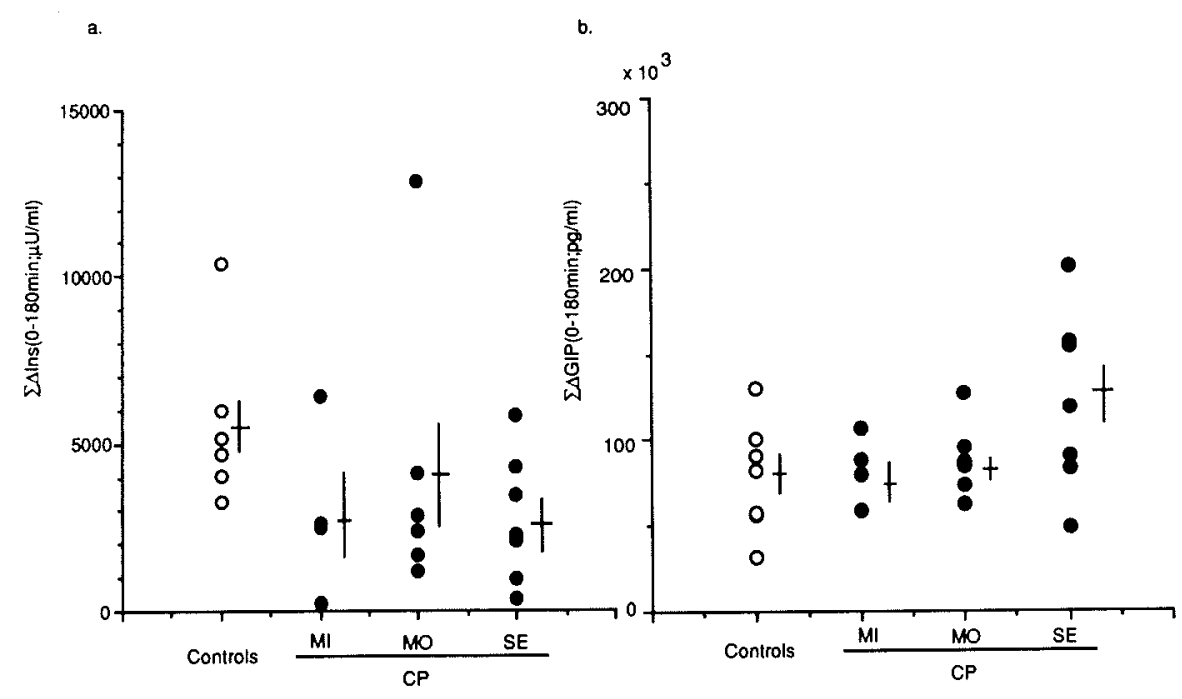

Fig. 4 The integrated incremental insulin (a, $\Sigma \Delta$ Ins) and GIP concentrations after the oral glucose load (b, $\Sigma \Delta$ GIP) in normal subjects (controls) and in CP patients with mild (MI), moderate (MO) and severe (SE) pancreatic exocrine dysfunction

without DM and normal subjects. Although the difference was not significant, the GIP response to oral glucose in CP patients seemed to be greater than in normal subjects (Fig. 2c).

Comparison between $C P$ patients grouped by the degree of exocrine dysfunction and normal subjects $\mathrm{CP}$ patients were divided into 3 groups according to the degree of pancreatic exocrine dysfunction (see Materials and Methods). The mean values of volume, mean bicarbonate concentration and amylase output of the duodenal juice determined in the CS test decreased with progressing pancreatic exocrine dysfunction (Table 1). The plasma glucose levels of $\mathrm{CP}$ patients with severe exocrine dysfunction were significantly higher than those of normal subjects not only in the fasting state but after the glucose ingestion. Their glucose levels tended to be even higher than the groups with mild or moderate exocrine dysfunction (Fig. 3a). The early insulin response was lost in $\mathrm{CP}$ patients. Among the groups of CP patients, CP patients with severe exocrine dysfunction showed the smallest insulin response (Fig. 3b). In the fasting state, plasma IRGIP concentrations were not significantly different between the groups of CP patients and normal subjects. The plasma IR-GIP levels were, however, significantly higher in CP patients with severe exocrine dysfunction than in normal subjects at 30,60 , 90 and $120 \mathrm{~min}$ after the glucose ingestion. Although the difference was not significant, the plasma GIP levels of CP patients with severe exocrine dysfunction tended to be higher than those with mild or moderate exocrine dysfunction (Fig. 3c).

\section{Relationship of the Insulin and GIP Responses to Oral Glucose in Patients with Exocrine Dysfunction}

There was a tendency for the integrated insulin response of $\mathrm{CP}$ patients to be lower than that of normal subjects irrespective of the grade of pancreatic exocrine dysfunction (Fig. 4a). Although the difference was not significant, the integrated GIP response of $\mathrm{CP}$ patients with severe exocrine dysfunction was higher than that of normal subjects or CP patients with mild or moderate exocrine dysfunction (Fig. 4b).

To investigate which factor in the CS test is most relevant to the increased GIP response in CP patients, the correlations between the plasma GIP levels at $30 \mathrm{~min}$ after the glucose ingestion and the values of volume, mean bicarbonate concentration and amylase output of the duodenal juice were examined. Among these factors, only amylase output showed a negative correlation with the plasma GIP level (Fig. 5).

Next, the correlation between the integrated insulin and the integrated GIP responses was examined (Fig. 6). In CP patients with severe exo- 


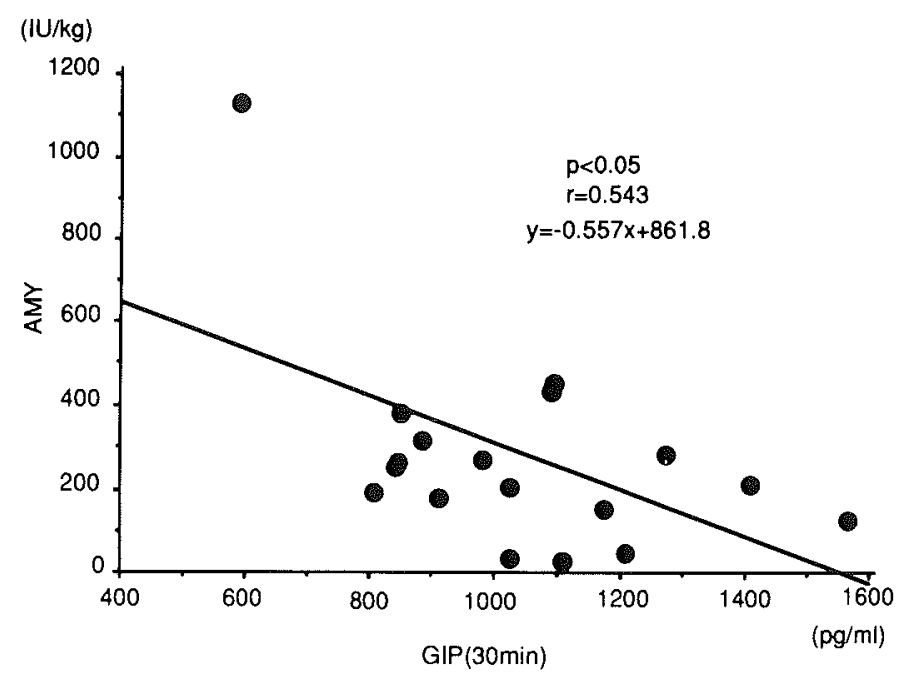

Fig. 5 The correlation between the plasma GIP levels at $30 \mathrm{~min}$ after the glucose ingestion (GIP, $30 \mathrm{~min}$ ) and the values of amylase output (AMY) of the duodenal juice in the CP patients

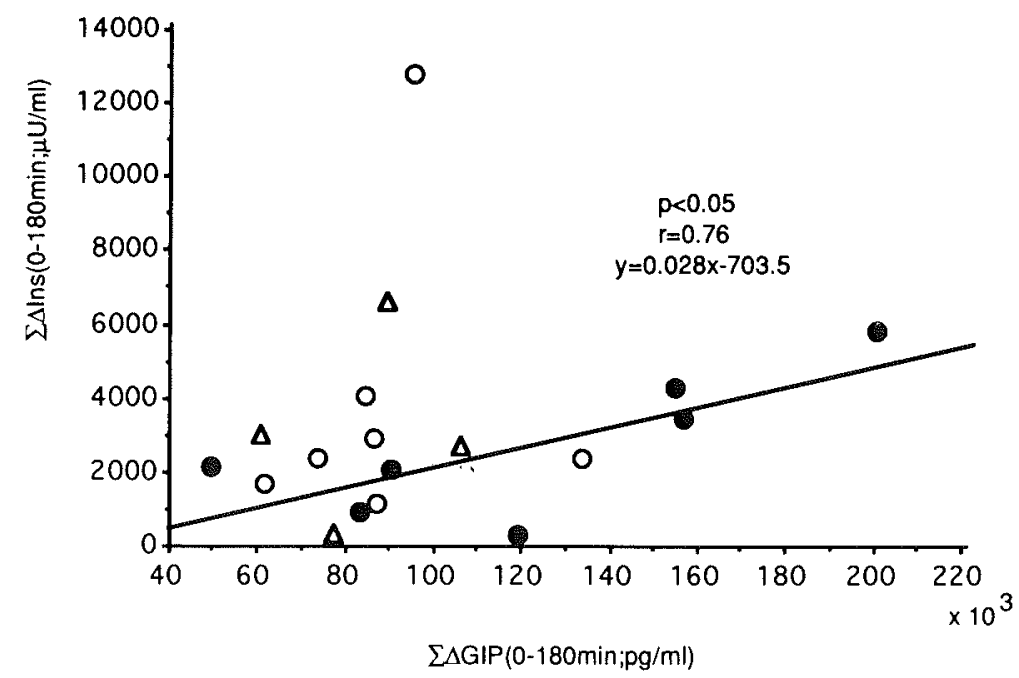

Fig. 6 The correlation between the integrated insulin ( $\Sigma \Delta$ Ins) and integrated GIP ( $\Sigma \Delta$ GIP) response to $75 \mathrm{~g}$ oral glucose in CP patients with mild (open triangles), moderate (open circles) and severe (closed circles) pancreatic exocrine dysfunction. The positive correlation was found only in the $\mathrm{CP}$ patients with severe exocrine dysfunction.

crine dysfunction, a linear positive correlation was found between the integrated insulin and integrated GIP responses to oral glucose $(y=0.028 x-$ $703.5, P<0.05)$, but such a correlation was not present in CP patients with mild or moderate exocrine dysfunction (Fig. 6).

\section{DISCUSSION}

To our knowledge, this is the first demonstration that plasma GIP concentrations in man were measured by a radioimmunoassay (RIA) for human GIP. The present assay system employed anti-syn- 
thetic human GIP serum and synthetic human GIP $(1-42)$ for the preparation of standard and tracer, while most of previous RIAs employed porcine GIP for the preparation of GIP standards and tracers (2). Porcine GIP differs from human GIP at positions 18 and 34 (37). These differences may play an important role in the marked variability of circulating human GIP levels so far reported (1, 29). The mean fasting plasma GIP level in normal subjects shown in this study was $399.7 \pm 21.2 \mathrm{pg} /$ $\mathrm{ml}$ which was equivalent to $80.3 \pm 4.3 \mathrm{pmol} / 1$.

The pattern of GIP response to $75 \mathrm{~g}$ oral glucose shown in this study also differed from the patterns reported by others $(13,38)$; In those studies, plasma GIP concentrations reached peak values at 45 or 60 min after the oral glucose load (5.5- and 2.3-fold higher than the basal values), decreased thereafter gradually to levels at $180 \mathrm{~min}$ that were still slightly higher than the basal values. In the present study, the circulating GIP concentrations remained at relatively constant levels (approximately 2-fold higher than the basal) from 30 to 180 min after the glucose ingestion. It has been described that elution profile of human plasma in gel permeation chromatography showed 3 immunoreactive GIP (IR-GIP) peaks $(9,15,29,34)$ : one high molecular weight component was eluted in the void volume of the column (Vo-IR-GIP), while the other 2 components at positions corresponding to molecular weights of approximately $8 \mathrm{kDa}$ and $5 \mathrm{kDa}$. The $5 \mathrm{kDa}$ GIP was suggested to be identical to authentic GIP $(9,33)$, while Vo-IR-GIP and $8 \mathrm{kDa}$ GIP may be a complex formed by the non-specific binding of GIP to a serum protein (12) but not a proform of $\operatorname{GIP}(33,41)$.

Previous studies on CP patients which examined GIP responses to oral glucose have produced contradictory data, probably because of the small number of patients investigated and because of the difference in the specificity of antisera employed (4, $5,27)$. The fasting plasma GIP levels of these patients were reported to be either higher or lower than normal subjects, and following ingestion of glucose, the plasma levels of GIP in these patients were either increased or decreased compared with normal subjects. In this study, we investigated 18 CP patients whose exocrine function had been fully evaluated, and demonstrated that circulating GIP levels following the oral administration of glucose are increased in CP patients with severe exocrine dysfunction. In addition, we have also demonstrated that the integrated GIP response to oral glucose in these patients correlates with the integrated insulin response. In this study, no significant difference was found in the plasma GIP levels between CP patients with mild or moderate exocrine dysfunction and normal subjects. In addition, no correlation was found between the integrated increments in plasma GIP and insulin concentrations after the glucose ingestion. The secretory response of GIP to oral glucose in CP patients may augment when their exocrine dysfunction progresses to severe grades and their insulin deficiency becomes manifest. In such pathological stages of CP, endogenous GIP may exert a stimulatory effect on insulin release. This notion is in agreement with the conclusion by Kalk and Vinik that in chronic pancreatitis, the glucose-stimulated pathway of $\beta$ cells for insulin secretion is defective, while the glucose-stimulated pathway of the entero-insular axis is impaired to a lesser extent (31, 46). Since the insulinotropic action of GIP has been shown only in the presence of hyperglycemia $(21,24,44)$, the positive correlation between the integrated GIP and insulin responses in CP patients with severe exocrine dysfunction may be caused by their high plasma glucose levels.

In contrast, when $\mathrm{CP}$ patients were divided into 2 groups according to whether they were complicated by DM or not, no significant difference was found between them in the values after the glucose load. In CP patients with DM, no positive correlation was noticed between the integrated GIP and insulin responses to oral glucose (data not shown), although their plasma glucose concentrations were significantly higher than normal subjects and CP patients without DM. These results suggest that DM in some of the CP patients in this study may not be caused solely by pancreatitis, that is some patients may have type 2 (non-insulin-dependent) DM. In fact, 6 out of $7 \mathrm{CP}$ patients with severe exocrine dysfunction (85.7\%) included in the present study had overt DM, while only 6 out of 10 DM patients $(60 \%)$ showed severe exocrine dysfunction by the CS test (Table 1). The heterogeneous etiology of diabetes should always be considered when the glucose tolerance of CP patients and their capacity for insulin secretion are investigated (3). In contrast to $C P$, the insulinotropic effect has been shown to be reduced or lost in type 2 DM $(28,32$, 35). Recent studies have presented evidence that the reduced incretin effect in type 2 DM may be partly caused by the decreased sensitivity of $\beta$ cells to $\operatorname{GIP}(28,36,39)$.

The present study demonstrated that the GIP response of CP patients to oral glucose is augment- 
ed when their exocrine dysfunction progresses. The finding implies that some events may occur in such conditions to increase the sensitivity of enteric GIP secreting cells (K cells) to luminal glucose (and probably to other stimuli) or to increase the number of $\mathrm{K}$ cells. Several possibilities have been proposed $(5,7,23)$ : 1) Insulin may turn off GIP release by a feedback mechanism: the decreased insulin secretion in CP patients may relieve the inhibition of GIP release by insulin (21). 2) C-peptide might mediate the negative feedback inhibition of GIP release (20). 3) Glucagon has been shown to produce a suppression of GIP release (22); the deficiency of glucagon in CP patients might reduce the inhibition of GIP release, although a relative hyperglucagonemia to plasma insulin concentrations has also been reported in this disease (30). 4) Diet-induced adaptation of $\mathrm{K}$ cells in $\mathrm{CP}$ patients might lead to the augmented GIP response because it has been reported that isocaloric diets of varied composition have a differential effect on GIP release (40). 5) The increased rate of glucose absorption in $\mathrm{CP}$ patients might augment the GIP secretion (26) because GIP secretion seems to be linked intimately with the active transport of glucose into $\mathrm{K}$ cells and its intracellular metabolism (18). 6) The relation between the GIP response and accelerated gastric emptying in CP patients has been discussed (5). Although there are many possibilities, no definite conclusion has been made so far on the regulation of GIP secretion from the intestine. Because the augmented GIP response to oral glucose may also be seen in type 2 diabetics (25), this phenomenon may not be caused by the etiologic factors of the disease, but may rather be caused by a mechanism secondary to the changes in several pathological states.

In conclusion, using a radioimmunoassay specific to human GIP, we have shown that the GIP response to oral glucose in CP patients became greater when their pancreatic insufficiency progresses, and that in such pathological stages, a linear positive correlation was obtained between the integrated plasma GIP and insulin responses to oral glucose. These demonstrations may suggest that, in patients with advanced $\mathrm{CP}$, the insulinotropic effect of GIP may be partially responsible for maintaining their insulin response to oral glucose.

The authors are grateful to Brent Bell for reading the manuscript.

Received 28 March 1994; and accepted 14 April 1994

\section{REFERENCES}

1. Alam M. J. and Buchanan K. D. (1980) Gastric inhibitory polypeptide (GIP) responses in diabetes using three different antibodies. Regul. Pept. 1, Suppl., S2

2. Alam M. J. and Buchanan K. D. (1993) Conflicting gastric inhibitory polypeptide data: possible causes. Diabetes Res. Clin. Pract. 19, 93-101

3. Bank S., Jackson W. P. U., Keller P. and Marks I. N. (1968) Serum-insulin response to glucose in 'pancreatic diabetes'. Postgrad. Med. J. 44, 214-217

4. Botha J. L., ViniK A. I. and Brown J. C. (1976) Gastric inhibitory polypeptide (GIP) in chronic pancreatitis. $J$. Clin. Endocrinol. Metab. 42, 791-797

5. Botha J. L., VINIK A. I. and CHILd P. T. (1978) Gastric inhibitory polypeptide in acquired pancreatic diabetes; Effects of insulin treatment. J. Clin. Endocrinol. Metab. 47, 543549

6. Brown J. C. (1971) A gastric inhibitory polypeptide. I. The amino acid composition and the tryptic peptides. Can. $J$. Biochem. 49, 255-261

7. Brown J. C., Buchan A. M. J., McIntosh C. H. S. and Pederson R. A. (1989) Gastric inhibitory polypeptide. In Handbook of Physiology, Section 6 (ed. Schultz S. G., Makhlouf G. M. and Rauner B. B.) American Physiological Society, Bethesda, pp. 404-430

8. Brown J. C. and Dryburgh J. R. (1971) A gastric inhibitory polypeptide. II. The complete amino acid sequence. Can. J. Biochem. 49, 867-872

9. Brown J. C., Dryburgh J. R., Ross S. A. and Dupré J. (1975) Identification and actions of gastric inhibitory polypeptide. Recent Prog. Horm. Res. 31, 487-532

10. Brown J. C., Mutt V. and Pederson R. A. (1970) Further purification of a polypeptide demonstrating enterogastrone activity. J. Physiol. 209, 57-64

11. Brown J. C., Pederson R. A., Jorpes J. E. and Mutt V. (1969) Preparation of a highly active enterogastrone. Can. J. Physiol. Pharmacol. 47, 113-114

12. Burhol P. G., Jorde R. and Waldum H. L. (1980) Radioimmunoassay of plasma gastric inhibitory polypeptide (GIP), release of GIP after a test meal and duodenal infusion of bile and immunoreactive plasma GIP components in man. Digestion 20, 336-345

13. Cataland S., Crockett S. E., Brown J. C. and MazzaFERRI E. L. (1974) Gastric inhibitory polypeptide (GIP) stimulation by oral glucose in man. J. Clin. Endocrinol. Metab. 39, 223-228

14. Cleator I. G. M. and Gourlay R. H. (1975) Release of immunoreactive gastric inhibitory polypeptide (IR-GIP) by cral ingestion of food substances. Amer. J. Surg. 130, 128135

15. Cole E. M. A., Alam M. J., Flanagan R. and Buchanan K. D. (1981) Molecular heterogeneity of gastric inhibitory polypeptide-like immunoreactivity (GIP-LI) in fasting human plasma and differential component response to oral glucose and fat. Diabetologia 21, 667

16. CReutzFeldt W. (1979) The incretin concept today. Diabetologia 16, 75-85

17. Creutzfeldt W. and Ebert R. (1985) New development in the incretin concept. Diabetologia 28, 565-573

18. Creutzfeldt W., Ebert R., Nauck M. and Stöckmann F. (1983) Disturbances of the entero-insular axis. Scand. $J$. Gastroenterol. 18, Suppl. 83, 111-119

19. DiMagno E. P., Layer P. and Clain J. E. (1993) Chronic 
pancreatitis. In The Pancreas. Second Ed. (ed. Go VLw, Dimagno E. P., Gardner J. D., Lebenthal E., Reber H. A. and Scheele G. A.) Raven Press, New York, pp. 665-706

20. Dryburgh J. R., Hampton S. M., Morgan L. M. and MARKS V. (1980) C-peptide-induced inhibition of GIP release. Regul. Pept. 1, Suppl., S28

21. Dupré J., Ross S. A., Watson D. and Brown J. C. (1973) Stimulation of insulin secretion by gastric inhibitory polypeptide in man. J. Clin. Endocrinol. Metab. 37, 826-828

22. Ebert R., Arnold R. and Creutzfeldt W. (1977) Lowering of fasting and food stimulated serum immunoreactive gastric inhibitory polypeptide (GIP) by glucagon. Gut 8, 121-127

23. Ebert R., Creutzfeldt W., Brown J. C., Frerichs H. and ARNOLD R. (1976) Response of gastric inhibitory polypeptide (GIP) to test meal in chronic pancreatitis -Relationship to endocrine and exocrine insufficiency-. Diabetologia 12, 609-612

24. Elahi D., Andersen D. K., Brown J. C., Debas H. T., HerShopf R. J., Raizes G. S., Tobin J. D. and Andres R. (1979) Pancreatic $\alpha$ - and $\beta$-cell response to GIP infusion in normal man. Amer. J. Physiol. 237, E185-E191

25. Elahi D., Andersen D. K., Muller D. C., Tobin J. D., Brown J. C. and ANDres R. (1984) The enteric enhancement of glucose-stimulated insulin release. The role of GIP in aging, obesity, and non-insulin-dependent diabetes mellitus. Diabetes 33, 950-957

26. Helman C. A., Barbezat G. O. and Bank S. (1976) Monosaccharide, water and electrolyte absorption in calcific pancreatitis. Proceeding of the 10th International Congress of Gastroenterology, Budapest, 339 (Abstract)

27. Jensen S. L., Lauridsen K. B., Christensen K. C. and NiELSEN O. V. (1981) Diminished gastric inhibitory polypeptide response to glucose administered orally in patients with chronic pancreatitis. Surg. Gynecol. Obstet. 153, 665668

28. Jones I. R., Owens D. R., Moody A. J., Luzio S., Morris T. and HAYES T. M. (1987) The effects of glucose-dependent insulinotropic polypeptide infused at physiological concentrations in normal and Type 2 (non-insulin-dependent) diabetic patients on glucose tolerance and $\beta$-cell secretion. Diabetologia 30, 707-712

29. Jorde R., Burhol P. G. and Schultz T. B. (1983) Fasting and postprandial plasma GIP values in man measured with seven different antisera. Regul. Pept. 7, 87-94

30. Kalk W. J., Vinik A. I., Bank S, Buchanan K. D., Keller P. and JACKSON W. P. U. (1974) Glucagon responses to arginine in chronic pancreatitis. Diabetes 23, 257-263

31. KalK W. J., Vinik A. I., BANK S., Keller P. and JACKSON W. P. U. (1974) Selective loss of beta cell response to glucose in chronic pancreatitis. Horm. Metab. Res. 6, 95-98

32. Krarup T. and Groop P.-H. (1991) Physiology and pathophysiology of GIP: a review. Scand. J. Clin. Lab. Invest. 51, 571-579

33. Krarup T., Holst J. J., Knuhtsen S., Moody A. J. and Nielsen O. V. (1987) Effect of porcine 8000 dalton immunoreactive gastric inhibitory polypeptide on the isolated perfused pig pancreas. Diabetes 36, Suppl. 1, 7A

34. Krarup T., Holst J. J. and Larsen K. L. (1985) Responses and molecular heterogeneity of IR-GIP after intraduodenal glucose and fat. Amer. J. Physiol. 249, E195-E200

35. Krarup T., Saurbrey N., Moody A. J., Kühl C. and MADSBAD S. (1987) Effect of gastric inhibitory polypeptide on $\beta$-cell function in type 1 and type II diabetes mellitus. Metabolism 36, 677-682

36. Meneilly G. S., Bryer-Ash M. and Elahi D. (1993) The effect of glyburide on $\beta$-cell sensitivity to glucose-dependent insulinotropic polypeptide. Diabetes Care 16, 110-114

37. Moody A. J., Thim L. and Valverde I. (1984) The isolation and sequencing of human gastric inhibitory peptide (GIP). FEBS Lett. 172, 142-148

38. Nauck M., Schmidt W. E., Ebert R., Strietzel J., Cantor P., Hoffmann G. and Creutzfeldt W. (1989) Insulinotropic properties of synthetic human gastric inhibitory polypeptide in man: Interactions with glucose, phenylalanine, and cholecystokinin-8. J. Clin. Endocrinol. Metab. 69, 654-662

39. Nauck M. A., Heimesaat M. M., Ørskov C., Holst J. J., Ebert R. and Creutzfeldt W. (1993) Preserved incretin activity of glucagon-like peptide 1 [7-36 amide] but not of synthetic human gastric inhibitory polypeptide in patients with Type-2 diabetes mellitus. J. Clin. Invest. 91, 301-307

40. O'Dorisio T. M. and CATALAND S. (1981) Effect of diet on GIP release. In Gut Hormones Second Ed. (ed. BLoom S. R. and POLAK J. M.) Churchill Livingstone, Edinburgh, pp. 269-272

41. Otte S. C., Mutt V., Mcintosh C. H. S. and Brown J. C. (1984) Purification and amino acid composition of an 8,000 dalton immunoreactive form of GIP. Dig. Dis. Sci. 29, Suppl., 63S

42. Pederson R. A. and Brown J. C. (1972) Inhibition of histamine-, pentagastrin-, and insulin-stimulated canine gastric secretion by pure gastric inhibitory polypeptide. Gastroenterology 62, 393-400

43. Raptis S., Rau R. M., Schröder K. E., Hartmann W., Faulhaber J. D., Clodi P. H. and Pfeiffer E. F. (1971) The role of the exocrine pancreas in the stimulation of insulin secretion by intestinal hormones. III. Insulin responses to secretin and pancreozymin, and to oral and intravenous glucose, in patients suffering from chronic insufficiency of the exocrine pancreas. Diabetologia 7, 160-167

44. Sarson D. L., Wood S. M., Kansal P. C. and Bloom S. R. (1984) Glucose-dependent insulinotropic polypeptide augmentation of insulin. Physiology or pharmacology? Diabetes 33, 389-393

45. Takebe T., Kolzumi H. and Yamagata S. (1976) Continuous secretin infusion with pancreozymin pretreatment as a pancreatic function test. Tohoku J. Exp. Med. 118, Suppl., 173-181

46. ViNiK A. I., KaLK W. J. and JaCKSON W. P. U. (1974) A unifying hypothesis for hereditary and acquired diabetes. Lancet I, 485-486

47. Yamagata S. et al. (1983) Explanation for the diagnosis of chronic pancreatitis by tests of pancreatic exocrine function. In The Criteria for The Clinical Diagnosis of Chronic Pancreatitis (ed. A committee of Investigation for Chronic Pancreatitis in The Japanese Society of Gastroenterology.) Igaku-Tosho-Press, pp. 29-32 (in Japanese) 